\title{
Practice patterns regarding regional corticosteroid treatment in noninfectious Uveitis: a survey study
}

\author{
Matthew McHarg ${ }^{1,2}$, LeAnne Young ${ }^{1,3}$, Natasha Kesav ${ }^{1,4}$, Mehmet Yakin ${ }^{1}$, H. Nida Sen ${ }^{1}$ and Shilpa Kodati ${ }^{*}$
}

\begin{abstract}
Background: Regional corticosteroid therapy for noninfectious uveitis is well-established but usage patterns have not been studied extensively. This study aims to assess practice patterns of retina and uveitis specialists regarding their preferences on the use of local corticosteroid therapy.

Methods: A 13-question survey was developed regarding the practice patterns of regional corticosteroid use in specific situations and populations. The survey was distributed to both the American Uveitis Society and Macula Society.

Results: Responses from 87 ophthalmologists were analyzed. The two most commonly used drugs were the dexamethasone intravitreal implant $\left(\mathrm{Ozurdex}^{\oplus}\right)$ and posterior sub-tenon's triamcinolone (also known as posterior sub-Tenon's Kenalog, or PSTK). Regional corticosteroids were used more frequently as first-line treatment in more than half of posterior uveitis cases when compared to anterior uveitis (39.1-46.0\% vs 10.3\%, respectively).

Respondents were more willing to use regional corticosteroids in more than half of unilateral uveitis cases than in bilateral cases (54.7\% vs $18.6 \%$, respectively). A majority of respondents (67.1\%) stated that they would avoid using regional corticosteroids in patients under 8 years old.

Conclusions: Our results demonstrate more frequent regional corticosteroid use in posterior segment uveitis, unilateral cases, and avoidance in younger pediatric patients. Overall, the variability in these responses highlights the need for guidelines regarding regional corticosteroid use.
\end{abstract}

Keywords: Regional corticosteroids, Noninfectious uveitis, Practice patterns, Survey study, Pediatrics

\section{Background}

The uveitides are a heterogenous group of inflammatory diseases and are a significant cause of blindness worldwide, accounting for up to approximately $5-15 \%$ of cases [1-4]. Uveitic diseases are caused by either infectious or noninfectious etiologies, with noninfectious cases comprising the majority of cases in developed countries [1, 5]. Uveitis can be anatomically classified into anterior, intermediate, posterior, and panuveitis depending on the predominant site of inflammation. Anterior uveitis is the

\footnotetext{
* Correspondence: shilpa.kodati@nih.gov

${ }^{1}$ National Eye Institute, National Institutes of Health, 10 Center Dr, 10/10N109, Bethesda, MD 20892, USA

Full list of author information is available at the end of the article
}

most common worldwide, followed by posterior and panuveitis, with intermediate uveitis being the least common $[5,6]$.

Corticosteroids are the standard of care treatment for noninfectious uveitis and can be administered topically, regionally, or systemically [7]. Regional delivery via corticosteroid injections was developed to maximize drug delivery to the ocular target tissue over a defined period of time and minimize systemic adverse effects that result from oral formulations [8,9] Regional corticosteroids are commonly used in the treatment of noninfectious uveitis, including in cases of active intraocular inflammation and uveitic macular edema [10-12]. Regional administration of corticosteroid is, however, associated 
with an increased risk of cataracts, ocular hypertension, glaucoma, and injection or implantation site related complications [11-13]. Despite these side effects, they provide several important benefits over systemic corticosteroids, including minimal systemic exposure, potentially longer-term local delivery, and improved patient adherence. Systemic corticosteroids are typically reserved for bilateral uveitis, systemic disease, or when topical/local therapies fail to control inflammation [14]. However, prolonged systemic therapy can result in numerous documented side effects including cardiovascular disease, osteoporosis, hyperglycemia, fat distribution, and general immunosuppression, among others [15].

A variety of regional corticosteroids are currently available for treatment of noninfectious uveitis. These include the preservative-free formulation of triamcinolone acetonide (Triesence, Alcon, Fort Worth, TX) administered intravitreally $[16,17]$ and the preservativecontaining formulation of triamcinolone acetonide (Kenalog, Bristol-Meyers Squibb, New York, NY) used off-label for posterior sub-tenon's injection [10, 11, 18, 19] . Other regional therapies include the bio-erodible dexamethasone intravitreal implant, Ozurdex (Allergan Inc., Irvine, CA) [20, 21], and the long-acting fluocinolone acetonide intravitreal implants such as Retisert (Bausch \& Lomb, Rochester, New York, NY) [22, 23] and Yutiq (EyePoint Pharmaceuticals, Watertown, MA) $[24,25]$.

Several surveys pertaining to the use of immunomodulatory therapy in noninfectious uveitis $[26,27]$ have previously been published. However, only one of these assessed the use of corticosteroid therapy in adult uveitis, and was focused only on systemic corticosteroid therapy [28]. To the best of our knowledge, there are no existing survey studies that focus on regional corticosteroid usage in uveitis; therefore, our survey queried clinicians about their use of six commonly used regional corticosteroids in specific situations to gain a better understanding of practice patterns.

\section{Methods}

\section{Survey}

A 13-question survey was developed using SurveyMonkey (Supplemental Appendix 1). The survey was open from June 2019 through August 2019 and distributed to two groups of specialists described below. The first 5 questions surveyed demographics of each respondent (Supplemental Appendix 1, Q1 - Q5). Next, the survey probed respondents about their practice patterns when treating noninfectious uveitis in different anatomic locations (Supplemental Appendix 1, Q6, Q7), as well as the specific types of local corticosteroid therapies used as first-line treatment (Supplemental Appendix 1, Q7, Q8, Q12). For these questions, respondents had a choice of answers based on a four-point Likert scale (never, infrequently, half of cases, most of cases).

The remaining questions asked about age cutoffs for using local steroid injections in children (Supplemental Appendix 1, Q9), the use of local corticosteroids as maintenance therapy (Supplemental Appendix 1, Q10, Q11), and whether the results of a recent clinical trial (the POINT trial) [29] affected their clinical practice (Supplemental Appendix 1, Q13).

\section{Survey population}

The American Uveitis Society is a highly selective group of uveitis specialists with $22.5 \%$ international membership. The Macula Society is another highly selective group with $28.5 \%$ international membership. Both societies require members to devote time to clinical care and/or research and to have several recent publications in peer-reviewed journals specific to immunology/inflammation or posterior segment disease, respectively. Links to the survey website were distributed through American Uveitis Society and Macula Society electronic mailing lists.

There is minimal overlap in their respective electronic mailing lists (24 individuals), and each respondent was only allowed to submit one survey response. Similar to the Esterberg et al. survey [27], these two groups were chosen as their members consist of uveitis and retina experts who are likely to have extensive experience with the use of regional corticosteroid therapy in noninfectious uveitis.

\section{Statistical analysis}

Results are reported as percentages of complete responses per question. During analytical interpretation, "never" and "infrequently" responses were combined as "never/infrequently" for ease of interpretation in three questions (Supplemental Appendix 1, Q6, Q7, Q8). Similarly, "half of the cases" and "most cases" responses were combined as "more than half of cases" for the same three questions.

\section{Results}

In total, 99 experts responded to the survey. Twelve of these respondents were excluded for filling out less than $85 \%$ of the survey, and a final number of 87 responses were used for analysis. No respondents submitted more than one survey. Sixty-one respondents $(70.1 \%)$ indicated that they were fellowship trained in uveitis. Most respondents (59 respondents, 67.8\%) received the survey through American Uveitis Society, while the remaining 28 respondents $(32.2 \%)$ completed the survey via the Macula Society. Sixty-four of the respondents (73.6\%) practiced in the United States, and 33 respondents 
(37.9\%) had been practicing for more than 20 years. Respondent characteristics are summarized in Table 1.

\section{Commonly used regional corticosteroid therapies}

The most commonly used therapies were the dexamethasone intravitreal implant (Ozurdex) (36.6\%) and posterior sub-tenon's triamcinolone (also known as posterior sub-Tenon's Kenalog, or PSTK) (34.9\%), followed by intravitreal triamcinolone acetonide (IVTA) (20.3\%). Fluocinolone acetonide intravitreal implants (Yutiq and Retisert) were rarely used. When separated by focus of practice (medical retina, surgical retina, and uveitis), the two most commonly used therapies were similar between these groups. Medical retina specialists used PSTK at a rate of $40.5 \%$, followed by Ozurdex at $32.4 \%$. Surgical retina used Ozurdex most followed by PSTK, at rates of $38.8 \%$ and $32.7 \%$, respectively. Similarly, uveitis specialists used Ozurdex (40.8\%) most frequently followed by PSTK (35.5\%). Furthermore, the rates of uveitis fellowship training did not impact which therapies were used, as both fellowship and non-fellowship trained specialists used Ozurdex and PSTK most commonly. Respondents who were uveitis fellowship trained commonly used Ozurdex at a rate of $39.2 \%$ and PSTK at $36.7 \%$, while respondents without fellowship training commonly used both Ozurdex and PSTK at a rate of $33.3 \%$.

Table 1 Respondent characteristics

\begin{tabular}{ll}
\hline & $\begin{array}{l}\geq \mathbf{8 5 \%} \text { completion } \\
(\mathbf{n = 8 7 )}\end{array}$ \\
\hline Electronic Mailing List & $59(67.8 \%)$ \\
American Uveitis Society & $26(29.9 \%)$ \\
Macula Society & $2(2.3 \%)$ \\
Both & \\
Fellowship training & $61(70.1 \%)$ \\
Uveitis fellowship trained & $26(29.9 \%)$ \\
Not uveitis fellowship trained & \\
Primary focus of practice & $20(23.0 \%)$ \\
Medical Retina & $25(28.7 \%)$ \\
Surgical Retina & $39(44.8 \%)$ \\
Uveitis & $3(3.5 \%)$ \\
Other & \\
Experience with treating uveitis & $21(24.1 \%)$ \\
$<5$ years & $14(16.1 \%)$ \\
$6-10$ years & $11(12.6 \%)$ \\
$10-15$ years & $8(9.2 \%)$ \\
$16-20$ years & $33(37.9 \%)$ \\
$>20$ years &
\end{tabular}

Use of regional corticosteroid therapy by anatomic location of uveitis

The data for different anatomic locations were divided into four subgroups: anterior uveitis, intermediate uveitis, posterior uveitis, and panuveitis. Nearly half of the respondents, $46.0 \%$, used regional corticosteroids as first-line therapy in more than half of intermediate uveitis, while an average of $40.2 \%$ of respondents used it as first-line in more than half of posterior and panuveitis cases. First-line use of regional corticosteroids was less common in anterior uveitis, with only $10.3 \%$ using them in more than half of cases.

\section{Use of specific regional corticosteroid therapies}

PSTK was the most frequently used first-line-therapy in intermediate uveitis with $31.8 \%$ using it first-line in more than half of cases. Ozurdex was used more frequently in posterior and panuveitis with $42.4 \%$ using it as first-line in more than half of cases. Lastly, results indicated that Yutiq and Retisert were rarely used in uveitis.

\section{Use of regional corticosteroid therapy for unilateral/} bilateral cases and in the presence of systemic disease A majority of respondents (54.7\%) were willing to use regional corticosteroids as first-line therapy in more than half of unilateral uveitis cases, while only $18.6 \%$ were willing to use them in more than half of bilateral cases. Regional corticosteroids were also used infrequently in the presence of systemic immune-mediated disease, as only $24.7 \%$ used them in more than half of these cases.

\section{Use of regional corticosteroid therapy in children}

Only $8.2 \%$ of respondents used regional corticosteroids as first-line therapy in children in more than half of cases. However, respondents were willing to use regional corticosteroids in children in certain cases. When asked about age cutoffs, $67.1 \%$ stated that they would avoid the use of regional corticosteroid therapy in children $\leq 8$ years old. Avoidance of regional corticosteroids decreased with increasing patient age, with $41.5 \%$ avoidance for children $\leq 13$ years old, and $9.8 \%$ avoidance in children $\leq 18$ years old.

\section{Use of local corticosteroid therapy as maintenance therapy}

Most respondents (72.1\%) were willing to use local corticosteroid injections as maintenance therapy, defined as either repeated injections or long acting slow release systems such as Retisert or Yutiq.. Those who used local corticosteroids as maintenance therapy did so sparingly, with $82.3 \%$ of respondents using them in less than $25 \%$ of cases. 


\section{Effects of POINT trial on practice patterns}

Respondents completed the survey approximately one year after the POINT Trial results were released publicly. A majority of respondents (57.5\%) reported their practice patterns did not change as a result of the POINT Trial.

\section{Discussion}

There are multiple factors influencing the selection of local corticosteroid therapies in the treatment of noninfectious uveitis, including availability, cost, and provider comfort with specific therapies, among others. Additionally, co-management with rheumatologists and/or other specialists often impacts therapeutic considerations. While clinical efficacy is still regarded as one of the principal factors in determining therapy selection, the differences in efficacy can be overshadowed by the aforementioned external factors and may have affected survey responses. Furthermore, there are few guidelines specifying how these therapies should be implemented in different clinical scenarios, giving rise to more variability. Thus, the goal of this survey was to assess contemporary practice patterns of retina and uveitis specialists regarding their use of regional corticosteroids as a way to better understand indications and variations in practice.

In terms of specific therapies, PSTK was most commonly used in intermediate uveitis $(38.8 \%$ of respondents used it in more than half of cases), while Ozurdex was most commonly used in posterior and panuveitis (42.4\% of respondents used it in more than half of cases). The preference for PSTK and Ozurdex compared to IVTA may be due to the increased risk of intraocular hypertension with IVTA compared to PSTK [30, 31], although this was not demonstrated in the POINT Trial [29]. Additionally, given that sterile endophthalmitis has also been reported with intravitreal administration of triamcinolone acetonide [32, 33], PSTK can be considered preferential to IVTA in situations where Triesence ${ }^{\circ}$ availability is limited. Lastly, separating these results by area of focus and fellowship training did not have a significant impact on the most commonly used therapies. This suggests that some consistency exists among all ophthalmologists regarding treatment of noninfectious uveitis.

Fluocinolone acetonide implants Yutiq and Retisert were used infrequently by respondents. The reasons for less frequent utilization of Yutiq can likely explained by both its high cost and the fact that it has only received approval from the US Food and Drug Administration (FDA) in 2018 [34]. Retisert, in contrast, requires invasive surgery and has significant side effects. For example, $90 \%$ and $45 \%$ of patients underwent cataract surgery and glaucoma surgery, respectively, in the 7-year Multicenter
Uveitis Steroid Treatment (MUST) trial [35]. Therefore, the Retisert implant is typically reserved for cases that require long-term treatment. Finally, cost and access to Retisert may contribute to is low usage, as one respondent commented that Retisert was not available in their country.

As expected, our results showed that use of regional corticosteroids was less common in anterior uveitis, with $89.7 \%$ of respondents using them as first-line in less than half of cases. This finding is unsurprising, given that topical corticosteroid eye drops are typically used as firstline treatment of anterior uveitis [36]. In contrast, the use of regional corticosteroids was common in posterior segment uveitis, with $39.1-46.0 \%$ of respondents using it first-line in more than half of cases. In addition, the survey found that regional corticosteroids were rarely used as maintenance therapy - of the respondents who used regional corticosteroids as maintenance therapy, most $(82.3 \%)$ did so in less than $25 \%$ of cases. This is likely due to concerns regarding the long-term cumulative effects of local corticosteroid treatment and the need for long-term immunomodulatory therapies in these patients.

Our results also show that clinicians were more likely to use regional corticosteroids in unilateral cases than bilateral uveitis $(54.7 \%$ vs $18.6 \%$ in more than half of cases, respectively). This can be explained by the general understanding that unilateral cases constitute optimal candidates for regional corticosteroid therapy in the absence of obvious contraindications $[37,38]$.

There is limited data reporting the use of corticosteroids in pediatric populations. Carpentier et al. surveyed pediatric ophthalmologists and uveitis specialists on the management of uveitis-associated pediatric cataracts. They reported $64.5-71.0 \%$ of uveitis specialists used regional corticosteroids in perioperative management of cataracts compared to $29.8-68.1 \%$ of pediatric ophthalmologists [39]. Additionally, in the recent consensus report from the Paediatric Ocular Inflammation Group, no consensus was reached regarding the use of periocular steroids in juvenile idiopathic arthritis-associated uveitis [40]. Although there are undoubtedly unique considerations for the use of regional corticosteroid therapy in pediatric populations, especially with the concern for cataract formation [41], our survey found that there are situations where uveitis specialists would consider using them in children under the age of 18 (90.2\% of specialists). Notably, our results show that avoidance of regional corticosteroid use in children decreased with patient age.

The POINT trial showed Ozurdex and IVTA to be superior to periocular steroid injections [29]. However, our survey did not show preferential use of Ozurdex compared to PSTK and the majority of respondents (57.5\%) 
reported the recent POINT trial did not change their practice patterns. There may not have been adequate time to see practice pattern changes, as the publication of the POINT trial occurred only 4 months prior to distribution of the survey. Another explanation may be the lack of access to Ozurdex, as $26.4 \%$ of respondents were from outside the US and some practices or institutional pharmacies may not have it readily available in their formulary.

Strengths of the study included the prospective design and distribution to subspecialty societies with expertise in treating uveitis. The strict membership requirements of American Uveitis Society and Macula Society targeted the survey to a large group of ophthalmologists that were experienced in treating uveitis patients. Another strength is that, to the best of our knowledge, this is the first survey study assessing practice patterns of local corticosteroid usage in both pediatric and adult patients. Also, our sample of 87 respondents is of comparable size to similar electronic surveys/questionnaires in uveitis that have included between 45 and 132 ophthalmologist responses [27, 28, 42-45].

This study is limited by the sample size. Additionally, since there are a variety of factors that affect prescribing in various global healthcare environments and situations, it is difficult to generalize and fully capture the exact reasons behind therapeutic decisions regarding local corticosteroids. In his survey of uveitis specialists, Cunningham notably discusses that there has been a lack of consensus among uveitis specialists across a multitude of practice patterns, ranging from toxoplasmosis to noninfectious uveitis treatments [46]. He describes the need for consistently updated evidence-based treatment guidelines to ensure that both specialists and non-specialists can maximize positive patient outcomes. No such guidelines exist regarding corticosteroid use in noninfectious uveitis; nevertheless, our study does provide useful information and highlight these patterns of regional corticosteroid use in a variety of populations, anatomic locations of uveitis, and specific therapies. In summary, our results demonstrate a preference for the use of Ozurdex and PSTK in posterior segment uveitis, the use of regional corticosteroids in unilateral disease, and less frequent use as maintenance therapy. More research is required to accurately determine practice patterns for the use of regional corticosteroid therapies in the treatment of noninfectious uveitis. We hope that the reported experiences of highly experienced uveitis specialists in this survey can help to lay a foundation for more comprehensive comparative studies and guidelines in the future.

\section{Abbreviations}

PSTK: posterior sub-tenon's triamcinolone, also known as posterior subtenon's Kenalog; IVTA: intravitreal triamcinolone acetonide; FDA: Food and Drug Administration

\section{Supplementary Information}

The online version contains supplementary material available at https://doi. org/10.1186/s12348-021-00281-z.

Additional file 1. Supplemental Appendix 1: Survey regarding regional corticosteroid treatment in noninfectious uveitis.

\section{Acknowledgements \\ Not applicable.}

\section{Authors' contributions}

NK and NS made substantial contributions to the conception, design, and acquisition of survey data. LY and MY analyzed the survey data regarding regional corticosteroid usage. MM, LY, and SK interpreted the data and were major contributors in writing and revising the manuscript. All authors read and approved the final manuscript.

\section{Funding}

NEl intramural Research Program and NIH Medical Research Scholars Program, a public-private partnership supported jointly by the NIH and contributions to the Foundation for the NIH from the Doris Duke Charitable Foundation, Genentech, the American Association for Dental Research, the Colgate-Palmolive Company, and other private donors. Open Access funding provided by the National Institutes of Health $(\mathrm{NIH})$.

\section{Availability of data and materials}

The datasets used and/or analysed during the current study are available from the corresponding author on reasonable request.

\section{Declarations}

Ethics approval and consent to participate

Not applicable.

Consent for publication

Not applicable.

\section{Competing interests}

The authors declare that they have no competing interests.

\section{Author details}

${ }^{1}$ National Eye Institute, National Institutes of Health, 10 Center Dr, 10/10N109, Bethesda, MD 20892, USA. ${ }^{2}$ George Washington University School of Medicine, Washington, DC 20052, USA. ${ }^{3}$ Cleveland Clinic Lerner College of Medicine, Cleveland, OH 44195, USA. ${ }^{4}$ University Hospitals Eye Institute, Cleveland, $\mathrm{OH}$ 44106, USA.

Received: 12 July 2021 Accepted: 15 December 2021

Published online: 04 January 2022

\section{References}

1. Nussenblatt RB (1990) The natural history of uveitis. Int Ophthalmol 14(5-6): 303-308. https://doi.org/10.1007/BF00163549

2. Suttorp-Schulten MS, Rothova A (1996) The possible impact of uveitis in blindness: a literature survey. Br J Ophthalmol 80(9):844-848. https://doi. org/10.1136/bjo.80.9.844

3. Dick AD, Tundia N, Sorg R, Zhao C, Chao J, Joshi A, Skup M (2016) Risk of ocular complications in patients with noninfectious intermediate Uveitis, posterior Uveitis, or Panuveitis. Ophthalmology 123(3):655-662. https://doi. org/10.1016/j.ophtha.2015.10.028

4. Durrani OM, Tehrani NN, Marr JE, Moradi P, Stavrou P, Murray PI (2004) Degree, duration, and causes of visual loss in uveitis. Br J Ophthalmol 88(9): 1159-1162. https://doi.org/10.1136/bjo.2003.037226

5. Tsirouki T, Dastiridou A, Symeonidis C, Tounakaki O, Brazitikou I, Kalogeropoulos C, Androudi S (2018) A focus on the epidemiology of Uveitis. Ocul Immunol Inflamm 26(1):2-16. https://doi.org/10.1080/0927394 8.2016 .1196713

6. Miserocchi E, Fogliato G, Modorati G, Bandello F (2013) Review on the worldwide epidemiology of uveitis. Eur J Ophthalmol 23(5):705-717. https:// doi.org/10.5301/ejo.5000278 
7. Jabs DA (2018) Immunosuppression for the Uveitides. Ophthalmology 125(2):193-202. https://doi.org/10.1016/j.ophtha.2017.08.007

8. Koronis S, Stavrakas P, Balidis M, Kozeis N, Tranos PG (2019) Update in treatment of uveitic macular edema. Drug Des Devel Ther 13:667-680. https://doi.org/10.2147/DDDT.S166092

9. Tempest-Roe S, Joshi L, Dick AD, Taylor SRJ (2013) Local therapies for inflammatory eye disease in translation: past, present and future. BMC Ophthalmol 13(1):39. https://doi.org/10.1186/1471-2415-13-39

10. Sallam A, Taylor SRJ, Habot-Wilner Z, Elgohary M, Do HH, McCluskey P, Lightman S (2012) Repeat intravitreal triamcinolone acetonide injections in uveitic macular oedema. Acta Ophthalmol 90(4):e323-e325. https://doi. org/10.1111/j.1755-3768.2011.02247.x

11. Leder HA, Jabs DA, Galor A, Dunn JP, Thorne JE (2011) Periocular triamcinolone acetonide injections for cystoid macular edema complicating noninfectious uveitis. Am J Ophthalmol 152(3):441-448 e2. https://doi.org/1 0.1016/j.ajo.2011.02.009

12. Sen HN, Vitale S, Gangaputra SS, Nussenblatt RB, Liesegang TL, Levy-Clarke GA, Rosenbaum JT, Suhler EB, Thorne JE, Foster CS, Jabs DA, Kempen JH (2014) Periocular corticosteroid injections in uveitis: effects and complications. Ophthalmology 121(11):2275-2286. https://doi.org/10.1016/j. ophtha.2014.05.021

13. Hunter RS, Lobo AM (2011) Dexamethasone intravitreal implant for the treatment of noninfectious uveitis. Clin Ophthalmol 5:1613-1621. https:// doi.org/10.2147/OPTH.S17419

14. LeHoang P (2012) The gold standard of noninfectious uveitis: corticosteroids. Dev Ophthalmol 51:7-28. https://doi.org/10.1159/000336676

15. Hoes JN, Jacobs JWG, Verstappen SMM, Bij/sma JWJ, van der Heijden GJMG (2009) Adverse events of low- to medium-dose oral glucocorticoids in inflammatory diseases: a meta-analysis. Ann Rheum Dis 68(12):1833-1838. https://doi.org/10.1136/ard.2008.100008

16. Steeples LR, Anand N, Moraji J, Jones NP (2018) Clinical outcomes of intravitreal preservative-free triamcinolone preparation (Triesence(R)) for cystoid macular Oedema and inflammation in patients with Uveitis. Ocul Immunol Inflamm 26(7):997-1004. https://doi.org/10.1080/09273948.2017.12 94185

17. Ganapathy PS, Lowder CY, Arepalli S, Baynes K, Li M, Bena J, Srivastava SK (2018) Treatment duration and side effect profile of long-term use of intravitreal preservative-free triamcinolone Acetonide in Uveitis. Am J Ophthalmol 194:63-71. https://doi.org/10.1016/j.ajo.2018.07.003

18. Kok H et al (2005) Outcome of intravitreal triamcinolone in uveitis. Ophthalmology 112(11):1916 e1-1916 e7

19. Tanner V, Kanski JJ, Frith PA (1998) Posterior sub-Tenon's triamcinolone injections in the treatment of uveitis. Eye (Lond) 12(Pt 4):679-685. https:// doi.org/10.1038/eye.1998.168

20. Lowder C et al (2011) Dexamethasone intravitreal implant for noninfectious intermediate or posterior uveitis. Arch Ophthalmol 129(5):545-553. https:// doi.org/10.1001/archophthalmol.2010.339

21. Taylor SR et al (2012) Dexamethasone implant in pediatric uveitis, Ophthalmology 119(11):2412.e2. https://doi.org/10.1016/.ophtha.2012.07.025

22. Pavesio C et al (2010) Evaluation of an intravitreal fluocinolone acetonide implant versus standard systemic therapy in noninfectious posterior uveitis. Ophthalmology 117(3):567-575

23. Callanan DG, Jaffe GJ, Martin DF, Pearson PA, Comstock TL (2008) Treatment of posterior uveitis with a fluocinolone acetonide implant: three-year clinical trial results. Arch Ophthalmol 126(9):1191-1201. https://doi.org/10.1001/a rchopht.126.9.1191

24. Jaffe GJ, Foster CS, Pavesio CE, Paggiarino DA, Riedel GE (2019) Effect of an injectable Fluocinolone Acetonide insert on recurrence rates in chronic noninfectious Uveitis affecting the posterior segment: twelve-month results, Ophthalmology 126(4):601-610. https://doi.org/10.1016/j.ophtha.2018.10.033

25. Jaffe GJ, Lin P, Keenan RT, Ashton P, Skalak C, Stinnett SS (2016) Injectable Fluocinolone Acetonide long-acting implant for noninfectious intermediate Uveitis, posterior Uveitis, and Panuveitis: two-year results. Ophthalmology 123(9):1940-1948. https://doi.org/10.1016/j.ophtha.2016.05.025

26. Dick AD, Rosenbaum JT, al-Dhibi HA, Belfort R Jr, Brézin AP, Chee SP, Davis JL, Ramanan AV, Sonoda KH, Carreño E, Nascimento H, Salah S, Salek S, Siak J, Steeples L, Accorinti M, Acharya N, Adan A, Agrawal R, Akkoc N, al Ghamdi S, al Ghamdi T, al Saati A, Alsabaani N, al-Shamarani M, Bachta A, Barisani-Asenbauer T, Beare N, Porto FBO, Blanco R, Yee ACS, Chandran V, Chiquet C, Chng HH, Cimbalas A, Cimino L, Cordero-Coma M, Cristobal C, Cuevas M, Eurico da Fonseca J, de Boer J, de la Torre A, de Schryver I,
Derzko-Dzulynsky L, Diaz-Valle D, Merino CED, Facsko A, Figueira L, Fonollosa A, Fortin E, Gale R, Galeazzi M, Garcia S, Garcia Ruiz de Morales JM, Gašperšič N, Goldstein D, Guedes M, Guex-Crosier Y, Gul A, Hamam R, Haroon M, Hasegawa K, Heiligenhaus A, Hooper C, Hwang YS, Hwang DK, Juanola X, Kaburaki T, Kadayifcilar S, Kempen J, Kezuka T, Kherani A, Kirsimäe M, Kotaniemi K, Kraut A, Kubicka-Trzaska A, Kuffova L, Lightman S, Lim L, Lim WK, McCluskey P, McGuire M, Mirabelli P, Miserocchi E, Misiuk-Hojło M, Muccioli C, Muñoz S, Murphy C, Murray PI, Nagy Z, Namba K, Neri P. Nguyen Q, O'Gradaigh D, Omair M, Otsa K, Ozyazgan Y, Pablo F, Paroli MP, Pleyer U, Poór G, Proença R, Rabinovitch T, Read R, Rebrov M, RecillasGispert C, Rothova A, Schwartzman S, Seve P, Sharma S, Sims J, Sohár N, Suhler E, Szántó S, Szepessy Z, Tappeiner C, Thorne J, Tugal Tutkun I, TurnoKręcicka A, van Calster J, van der Horst-Bruinsma I, Vidovič Valentinčič N, Vitale A, Voorduin Ramos S, Vukojevic N, Wakefield D, Willermain F, Yalcindag N, Yamamoto JH, Yeh S, Zemaitiene R, Ziouzina O (2018) Guidance on noncorticosteroid systemic immunomodulatory therapy in noninfectious Uveitis: fundamentals of care for UveitiS (FOCUS) initiative. Ophthalmology 125(5):757-773. https://doi.org/10.1016/j.ophtha.2017.11.017

27. Esterberg E, Acharya NR (2012) Corticosteroid-sparing therapy: practice patterns among uveitis specialists. J Ophthalmic Inflamm Infect. 2(1):21-28. https://doi.org/10.1007/s12348-011-0047-5

28. Nguyen QD, Hatef E, Kayen B, Macahilig CP, Ibrahim M, Wang J, Shaikh O, Bodaghi B (2011) A cross-sectional study of the current treatment patterns in noninfectious uveitis among specialists in the United States. Ophthalmology 118(1):184-190. https://doi.org/10.1016/j.ophtha.2010.03.029

29. Thorne JE, Sugar EA, Holbrook JT, Burke AE, Altaweel MM, Vitale AT, Acharya NR, Kempen JH, Jabs DA, Multicenter Uveitis Steroid Treatment Trial Research Group (2019) Periocular triamcinolone vs. intravitreal triamcinolone vs. intravitreal dexamethasone implant for the Treatment of Uveitic macular edema: the PeriOcular vs. INTravitreal corticosteroids for uveitic macular edema (POINT) trial. Ophthalmology 126(2):283-295. https://doi.org/10.101 6/j.ophtha.2018.08.021

30. Roth DB, Verma V, Realini T, Prenner JL, Feuer WJ, Fechtner RD (2009) Longterm incidence and timing of intraocular hypertension after intravitreal triamcinolone acetonide injection. Ophthalmology 116(3):455-460. https:// doi.org/10.1016/j.ophtha.2008.10.002

31. Hirano Y, Ito T, Nozaki M, Yasukawa T, Sakurai E, Yoshida M, Ogura Y (2009) Intraocular pressure elevation following triamcinolone acetonide administration as related to administration routes. Jpn J Ophthalmol 53(5): 519-522. https://doi.org/10.1007/s10384-009-0692-5

32. Wang LC, Yang CM (2005) Sterile endophthalmitis following intravitreal injection of triamcinolone acetonide. Ocul Immunol Inflamm 13(4):295-300. https://doi.org/10.1080/09273940590951007

33. Nelson ML et al (2003) Infectious and presumed noninfectious endophthalmitis after intravitreal triamcinolone acetonide injection. Retina 23(5):686-691. https://doi.org/10.1097/00006982-200310000-00014

34. U.S. Food and Drug Administration. Drug Approval Package: Yutiq. 2018. https://www.accessdata.fda.gov/drugsatfda_docs/nda/2018/210331Orig1 s000Approv.pdf. Accessed 15 May 2020

35. Writing Committee for the Multicenter Uveitis Steroid Treatment, T et al (2017) Association between long-lasting Intravitreous Fluocinolone Acetonide implant vs systemic anti-inflammatory therapy and visual acuity at 7 years among patients with intermediate, posterior, or Panuveitis. JAMA 317(19):1993-2005

36. Jabs DA, Rosenbaum JT, Foster CS, Holland GN, Jaffe GJ, Louie JS, Nussenblatt RB, Stiehm ER, Tessler H, van Gelder RN, Whitcup SM, Yocum D (2000) Guidelines for the use of immunosuppressive drugs in patients with ocular inflammatory disorders: recommendations of an expert panel. Am J Ophthalmol 130(4):492-513. https://doi.org/10.1016/S0002-9394(00)00659-0

37. Takeuchi M, Kanda T, Kaburaki T, Tanaka R, Namba K, Kamoi K, Maruyama K, Shibuya E, Mizuki N (2019) Real-world evidence of treatment for relapse of noninfectious uveitis in tertiary centers in Japan: a multicenter study. Medicine (Baltimore) 98(9):e14668. https://doi.org/10.1097/MD. 0000000000014668

38. Barry RJ, Nguyen QD, Lee RW, Murray PI, Denniston AK (2014) Pharmacotherapy for uveitis: current management and emerging therapy. Clin Ophthalmol 8:1891-1911. https://doi.org/10.2147/OPTH.S47778

39. Carpentier SJ, Jung JL, Patnaik JL, Pecen PE, Palestine AG (2020) A crosssectional online survey identifies subspecialty differences in the Management of Pediatric Cataracts Associated with Uveitis. Ophthalmol Ther 9(2):293-303. https://doi.org/10.1007/s40123-020-00245-x 
40. Solebo AL, Rahi JS, Dick AD, Ramanan AV, Ashworth J, Edelsten C, Members of the POIG Uveitis Delphi Group (2020) Areas of agreement in the management of childhood non-infectious chronic anterior uveitis in the UK. Br J Ophthalmol 104(1):11-16. https://doi.org/10.1136/bjophthalmol-201 8-313789

41. Patel CC, Mandava N, Oliver SCN, Braverman R, Quiroz-Mercado H, Olson JL (2012) Treatment of intractable posterior uveitis in pediatric patients with the fluocinolone acetonide intravitreal implant (Retisert). Retina 32(3):537542. https://doi.org/10.1097//AE.0b013e31822058bb

42. Sen HN, Grange L, Akanda M, Fox A (2017) Autoimmune retinopathy: current concepts and practices (an American ophthalmological society thesis). Trans Am Ophthalmol Soc 115:T8

43. Ozzello DJ, Palestine AG (2015) Factors affecting therapeutic decisions in intermediate and posterior uveitis. Am J Ophthalmol 159(2):213-220 e3. https://doi.org/10.1016/j.ajo.2014.10.015

44. Burkholder BM, Moradi A, Thorne JE, Dunn JP (2015) The dexamethasone intravitreal implant for noninfectious Uveitis: practice patterns among Uveitis specialists. Ocul Immunol Inflamm 23(6):444-453. https://doi.org/1 0.3109/09273948.2015.1070180

45. Palestine AG, Singh JK, Kolfenbach JR, Ozzello DJ (2016) Specialty practice and cost considerations in the Management of Uveitis Associated with Juvenile Idiopathic Arthritis. J Pediatr Ophthalmol Strabismus 53(4):246-251. https://doi.org/10.3928/01913913-20160505-01

46. Cunningham ET Jr (2012) Surveying Uveitis specialists - a call for consensus. J Ophthalmic Inflamm Infect 2(2):61-63. https://doi.org/10.1 007/s12348-012-0061-2

\section{Publisher's Note}

Springer Nature remains neutral with regard to jurisdictional claims in published maps and institutional affiliations.

\section{Submit your manuscript to a SpringerOpen ${ }^{\circ}$ journal and benefit from:}

- Convenient online submission

- Rigorous peer review

- Open access: articles freely available online

- High visibility within the field

- Retaining the copyright to your article

Submit your next manuscript at $\boldsymbol{\nabla}$ springeropen.com 